\title{
Immunogenicity of subcutaneous TNF inhibitors and its clinical significance in real-life setting in patients with spondyloarthritis
}

\author{
J. Hiltunen ${ }^{1}$ (1) $\cdot$ P. Parmanne ${ }^{1} \cdot$ T. Sokka $^{2,3} \cdot$ T. Lamberg $^{4} \cdot$ P. Isomäki ${ }^{5} \cdot$ O. Kaipiainen-Seppänen ${ }^{6} \cdot$ R. Peltomaa ${ }^{1}$.

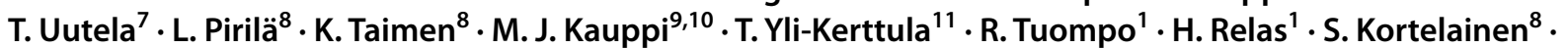 \\ K. Paalanen ${ }^{2,3} \cdot$ J. Asikainen ${ }^{2,3} \cdot$ P. Ekman ${ }^{11}$ - A. Santisteban ${ }^{15} \cdot$ K.-L. Vidqvist ${ }^{5} \cdot$ K. Tadesse $^{1} \cdot$ M. Romu ${ }^{1}$. J. Borodina ${ }^{2,3}$.

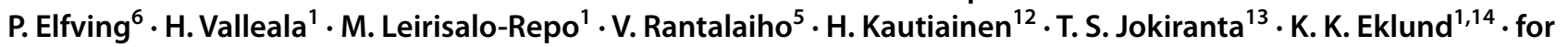 \\ the FinADASpA Study Group
}

Received: 29 April 2021 / Accepted: 17 July 2021 / Published online: 6 August 2021

(c) The Author(s) 2021

\begin{abstract}
Key messages Considerable proportion of patients with SpA have been immunized to the subcutaneous anti-TNF drug they are using. Concomitant use of MTX protects from immunization, whereas SASP does not. Patients with SpA using subcutaneous anti-TNF drugs can benefit from monitoring of the drug trough levels.

Abstract Immunization to biological drugs can lead to decreased efficacy and increased risk of adverse effects. The objective of this cross-sectional study was to assess the extent and significance of immunization to subcutaneous tumor necrosis factor (TNF) inhibitors in axial spondyloarthritis (axSpA) patients in real-life setting. A serum sample was taken 1-2 days before the next drug injection. Drug trough concentrations, anti-drug antibodies (ADAb) and TNF-blocking capacity were measured in 273 patients with axSpA using subcutaneous anti-TNF drugs. The clinical activity of SpA was assessed using the Bath AS Disease Activity Index (BASDAI) and the Maastricht AS Entheses Score (MASES). ADAb were found in 11\% of the 273 patients: in 21/99 (21\%) of patients who used adalimumab, in 0/83 (0\%) of those who used etanercept, in 2/79 (3\%) of those who used golimumab and in 6/12 (50\%) of those who used certolizumab pegol. Use of methotrexate reduced the risk of formation of ADAb, whereas sulfasalazine did not. Presence of ADAb resulted in decreased drug concentration and reduced TNF-blocking capacity. However, low levels of ADAb had no effect on TNF-blocking capacity and did not correlate with disease activity. The drug trough levels were below the consensus target level in $36 \%$ of the patients. High BMI correlated with low drug trough concentration. Patients with low drug trough levels had higher disease activity. The presence of anti-drug antibodies was associated with reduced drug trough levels, and the patients with low drug trough levels had higher disease activity. The drug trough levels were below target level in significant proportion of patients and, thus, measuring the drug concentration and ADAb could help to optimize the treatment in SpA patients.
\end{abstract}

Keywords Spondyloarthritis · Ankylosing spondylitis · Biological therapy $\cdot$ Anti-drug antibodies $\cdot$ Disease activity Therapeutic drug monitoring

Presented at: The preliminary results of this study were presented as an abstract presentation in the EULAR congress in Madrid 2017 (Hiltunen J, Parmanne P, Sokka-Isler T et al. OP0024 Drug trough levels and antidrug antibodies in nonselected ankylosing spondylitis patients using self-injected anti-tnf drugs. Ann Rheum Dis 2017;76:61).

The members of "FinADASpA Study Group" is present in the Acknowledgements section.

J. Hiltunen

johanna.hiltunen@hus.fi

Extended author information available on the last page of the article

\section{Background}

Development of anti-drug-antibodies (ADAb) to biological drugs can lead to low serum drug levels, reduced drug survival, loss of therapeutic response, and adverse events, such as infusion reactions. Immunogenicity of biological therapies has been studied extensively in rheumatoid arthritis (RA), but clearly less is known about the role of immunogenicity in the treatment of patients with spondyloarthritis $(\mathrm{SpA})$ and ankylosing spondylitis (AS). In some studies, the development of ADAb has resulted in reduced efficacy, whereas in 
other studies no correlation between the presence of $\mathrm{ADAb}$ and disease activity has been observed. Anti-infliximab antibodies have been observed in 15-29\% of AS patients [1] and SpA patients [2-4]. Development of anti-infliximab antibodies was associated with higher disease activity, lower infliximab trough levels and higher rate of infusion related reactions $[1,3,4]$. Anti-adalimumab antibodies have been observed in approximately $30 \%$ of AS and axSpA patients, and they have been associated with lower or undetectable serum drug levels and lower rate of response [5-7]. However, no association between $\mathrm{ADAb}$ against adalimumab and the disease activity was observed in patients with peripheral SpA [8], AS [9] or, according to a meta-analysis, AS or other SpA [10]. Immunogenicity of etanercept is negligible in $\operatorname{SpA}[11,12]$ and AS patients [13]. Immunogenicity of golimumab has been reported to be low in patients with AS [14, 15] and SpA [16], and the presence of antibodies against golimumab has not been associated with lower clinical response [15, 16]. Prevalence of anti-certolizumab pegol ADAb has been reported to be low in patients with SpA [17] but relatively high in RA patients [18].

In addition to the presence of ADAb, also low drug trough level has been shown to result in lower clinical response in RA [19-24], but it is not clear whether this is true also in SpA.

Concomitant use of conventional synthetic disease-modifying antirheumatic drugs (csDMARD) has been shown to reduce the immunogenicity of biological drugs in RA, Crohn's disease, or juvenile idiopathic arthritis patients using infliximab or adalimumab [25, 26]. Furthermore, concomitant use of csDMARD leads to better response in RA patients treated with tumor necrosis factor (TNF) inhibitors [27]. According to the recent international guidelines, csDMARD are not recommended for the treatment of axial SpA [28]. However, in practice, sulfasalazine (SASP) or methotrexate (MTX) are often used as monotherapy or in combination with biological DMARD. It is not known whether MTX can prevent the formation of ADAb in patients with SpA and the evidence of the benefit of concomitant use of csDMARD in SpA is somewhat conflicting [3, 4, 7, 28-33].

The aim of this study was to determine the extent and significance of immunization to anti-TNF drugs in reallife setting in unselected SpA patients with axial disease, and to assess the contribution of factors such as body mass index (BMI) and concomitant use of csDMARD on the immunogenicity.

\section{Materials and methods}

\section{Patients}

A total of 313 patients with $\mathrm{SpA}$ were enrolled to this national multicenter cross-sectional clinical study. Patients were recruited from 8 Finnish rheumatological outpatient clinics. The inclusion criteria were fulfillment of the classification criteria either by the 1984 New York criteria for AS or by the ASAS criteria for axial SpA (axSpA), and treatment with subcutaneous anti-TNF therapy (adalimumab, etanercept, golimumab or certolizumab pegol).

The exclusion criteria included diagnosis of psoriasis, psoriatic arthritis, or inflammatory bowel disease, inability to comprehend the consent form, concomitant csDMARD medication other than MTX or SASP, or glucocorticoid use of higher than $10 \mathrm{mg}$ daily dose of prednisone or equivalent.

\section{Methods}

The patients were recruited to the study during their normal visit to the rheumatology clinic during 2014-2015. Patients who were treated with subcutaneous anti-TNF agents, were recruited from 8 Finnish rheumatological outpatient clinics. The disease activity, function and enthesitis score were assessed during the visit by determination of Bath AS Disease Activity Index (BASDAI) [34], Maastricht AS Enthesis Score (MASES) [35] and Bath Ankylosing Spondylitis Functional Index (BASFI) [36]. BASDAI and BASFI are patient-reported measurements of the disease activity and the level of functional impairment, respectively, on a visual scale. MASES is based on clinical evaluation of tenderness in 13 enthesial sites. Clinical evaluation including Schober's test and occipital-wall measurement, BMI, C-reactive protein (CRP) and erythrocyte sedimentation rate (ESR) were measured. The blood sample for drug trough concentration and ADAb was taken within $48 \mathrm{~h}$ before the next injection of the drug.

The serum samples were coded and stored at $-70{ }^{\circ} \mathrm{C}$ before analysis. Trough concentration of the anti-TNF drugs was measured with commercial capture-type enzyme-linked immunosorbent assay (Promonitor ELISA, Progenika Biopharma) in a clinical laboratory (United Medix Laboratories) following the accreditation standards for clinical diagnostics (EN ISO/IEC 17025 and EN ISO 15189). The level of $\mathrm{ADAb}$ were measured with radioimmunoassay (Sanquin laboratories, Amsterdam, The Netherlands). TNF-blocking capacity (RGA index) reflects the capacity of patient's serum to neutralize further added TNF to the serum, and thus reflects the remaining capacity of the anti-TNF drug in the patient's blood to neutralize TNF. The TNF-blocking capacity of the sera was assessed using a cell-based reporter gene assay (RGA) set up in United Medix Laboratories (Helsinki, Finland) [37]. The RGA index used in this study has been obtained from samples diluted 1:75 using the equation RGA index $=1 /$ RFU (relative fluorescence units).

ADAb values $\geq 12 \mathrm{AU} / \mathrm{mL}$ were considered positive. Drug trough levels $<0.1 \mu \mathrm{g} / \mathrm{mL}$ were considered undetectable, and trough levels $<0.5 \mu \mathrm{g} / \mathrm{mL}$ were considered very 
low. The drug trough level was considered to be in the reference range if the level was $5-10 \mu \mathrm{g} / \mathrm{mL}$ for adalimumab, and thus low if the level was $<5 \mu \mathrm{g} / \mathrm{mL}[20,38]$. The drug trough level was considered to be low if the level was $<1242 \mu \mathrm{g} /$ $\mathrm{mL}$ for etanercept [21], $<1.4 \mu \mathrm{g} / \mathrm{mL}$ for golimumab [22, 39], and $<9 \mu \mathrm{g} / \mathrm{mL}$ for certolizumab pegol [18]. Confirmed upper limit of the target drug level is not available for etanercept, golimumab and certolizumab pegol. Very low drug trough level was defined as being as low or lower than the lowest $1 \%$ of drug concentration results from samples in which no $\mathrm{ADAb}$ were detected. Low drug trough level was defined as being between 1 and $15 \%$ of drug concentration results from samples without ADAb.

\section{Statistical methods}

The descriptive statistics are presented as means with SDs, as medians with IQR or as counts with percentages. Statistical comparisons between the groups were made using the $t$ test, chi-square test, or analysis of variance. In the case of violation of the assumptions (non-normality), a bootstraptype test was used. To determine characteristics associated with detected ADAb, multivariate logistic regression model was used. Correlation coefficients were calculated by the Spearman method, using Sidak-adjusted probabilities. The normality of the variables was tested by using the Shapiro-Wilk $W$ test. All analyses were performed using STATA software (version 15.0), StataCorp, LP, Texas, USA.

The study protocol was approved by the Ethical Review Board of the Joint Authority for the Hospital District of Helsinki and Uusimaa (108/13/03/01/2014).

\section{Results}

\section{Characteristics of the patient cohort}

Of the 313 patients who gave their consent to the study, 273 gave a blood sample, and were included into the study. Of these patients $180(66 \%)$ were male, 99 (36\%) used adalimumab, 83 (30\%) etanercept, 79 (29\%) golimumab, and 12 (4\%) certolizumab pegol. Of the patients 157 (58\%) were using their first biologic drug, and of them $72 \%$ were male. The first biologic drug was used by $56(57 \%)$ of the patients in adalimumab group, $50(60 \%)$ in etanercept group, 43 (54\%) in golimumab group and $8(67 \%)$ in certolizumab pegol group. The characteristics of the patient cohort are presented in Table 1.

Mean duration of disease was 10 years for those who used their first biologic drug and 15 years for those who had used one or more biologic drugs previously $(p<0.001)$. As expected the mean age was higher in the group who had had prior biologic treatment ( 47 vs. 43 years, $p=0.003$ ). The two groups did not differ with respect to weight, BMI, mean result of Schober's test, occipital-wall test, or CRP, nor with respect to the use of concomitant csDMARD or glucocorticoid therapy. ESR was lower in those who used their first biologic drug $(p=0.015)$ (data not shown).

\section{The prevalence of anti-drug antibodies}

ADAb were found in 29 (11\%) of the 273 patients. ADAb were observed in 21 of the 99 (21\%) patients who used adalimumab, in 0 of $83(0 \%)$ of those who used etanercept, in two of the 79 (3\%) of those who used golimumab and in six of the $12(50 \%)$ of those who used certolizumab pegol $(p<0.001)$. There was no difference in the prevalence of ADAb between those patients who used their first biologic drug, as compared to those who had used previously one or more biologic drugs.

\section{Demographic and clinical factors affecting drug trough concentration, presence of ADAb and the TNF-blocking capacity}

Higher BMI, MASES and ESR correlated with lower drug trough concentration. Older age correlated with higher drug trough concentration and better TNF-blocking capacity (higher RGA index). Disease duration and the length of biologic treatment correlated with higher RGA index. The results are presented in Table 2.

The patients using adalimumab were analyzed also as a separate group because of the low number of patients in the certolizumab pegol group and low rate of ADAb positivity in the etanercept and golimumab groups. Increased risk of immunization in adalimumab users was associated with longer duration of the disease and higher BMI, whereas younger age and the length of all biologic treatment were associated with decreased risk of ADAb positivity. HLAB27 status or gender was not associated with the ADAb prevalence. The results are presented in Table 3.

\section{Effect of concomitant medication on prevalence of anti-drug antibodies}

The proportion of patients who used any csDMARD were $56 \%, 49 \%, 54 \%$, and $75 \%$, in patients using adalimumab, etanercept, golimumab, and certolizumab pegol, respectively. Concomitant glucocorticoid use was uncommon, except in patients using certolizumab pegol, of whom $25 \%$ used glucocorticoids. ADAb were detected in $12 \%$ of patients using concomitant MTX as compared to $28 \%$ of those who did not use MTX ( $p=0.048$ : adjusted for gender, disease duration, age, BMI, HLA-B27, and the time of use of biological drug). SASP was not associated with immunization; there were $6 \mathrm{ADAb}$-positive vs. $59 \mathrm{ADAb}$-negative 
Table 1 Characteristics of the patient cohort

\begin{tabular}{|c|c|c|c|c|c|}
\hline & Adalimumab $N=99$ & Etanercept $N=83$ & Golimumab $N=79$ & Certolizumab pegol $N=12$ & $p$ value \\
\hline Number of men, $n(\%)$ & $60(61)$ & $53(64)$ & $59(75)$ & $8(67)$ & 0.25 \\
\hline Age, mean (SD) & $46(11)$ & $44(12)$ & $42(11)$ & $47(13)$ & 0.12 \\
\hline BMI & $26.1(4.6)$ & $26.2(4.5)$ & $26.8(4.7)$ & $25.6(3.9)$ & 0.74 \\
\hline Disease duration (years), mean (SD) & $15.8(10.3)$ & $14.8(10.1)$ & $10.9(9.4)$ & $8.8(6.9)$ & $<0.001$ \\
\hline BASDAI, mean (SD) & $1.7(1.8)$ & $2.1(1.8)$ & $2.0(1.7)$ & $1.2(1.2)$ & 0.12 \\
\hline MASES, mean (SD) & $0.4(1.4)$ & $0.4(1.4)$ & $0.4(1.3)$ & $0.1(0.3)$ & 0.057 \\
\hline BASFI, mean (SD) & $1.5(2.0)$ & $2.0(2.0)$ & $1.6(1.5)$ & $1.2(1.0)$ & 0.24 \\
\hline ESR, mean (SD) & $8(8)$ & $9(9)$ & $6(6)$ & $5(6)$ & 0.064 \\
\hline CRP, mean (SD) & $3(4)$ & $4(5)$ & $3(3)$ & $3(4)$ & 0.53 \\
\hline HLA-B27, $n(\%)$ & $87(94)$ & $74(95)$ & $69(90)$ & $12(100)$ & 0.58 \\
\hline $\begin{array}{l}\text { Treatment duration with current } \\
\text { medicine (months) median (IQR), } \\
\text { range }\end{array}$ & $46(22.71)[1-126]$ & $46(18.71)[2-131]$ & $17(9.33)[2-101]$ & $7(3.10)[3-23]$ & $<0.001$ \\
\hline $\begin{array}{l}\text { Duration of all biologic treatment } \\
\text { (months), median (IQR), range }\end{array}$ & $57(35.104)[3,172]$ & 55 (31.91) [2-177] & $25(16.55)[2-210]$ & $8(3.60)[3-110]$ & $<0.001$ \\
\hline \multicolumn{6}{|l|}{ DMARD, $n(\%)$} \\
\hline None & $44(44)$ & $42(51)$ & $36(46)$ & $3(25)$ & 0.40 \\
\hline Methotrexate & $41(41)$ & $25(30)$ & $32(41)$ & $6(50)$ & 0.30 \\
\hline Sulfasalazine & $21(21)$ & $22(27)$ & $17(22)$ & $5(42)$ & 0.39 \\
\hline Leflunomide & $1(1)$ & $0(0)$ & $0(0)$ & $0(0)$ & 0.99 \\
\hline Peroral glucocorticoid, $n(\%)$ & $5(5)$ & $2(2)$ & $3(4)$ & $3(25)$ & 0.039 \\
\hline \multicolumn{6}{|l|}{ Previous biologic treatment } \\
\hline Number, $n(\%)$ & & & & & 0.69 \\
\hline 0 & $56(57)$ & $50(60)$ & $43(54)$ & $8(67)$ & \\
\hline 1 & $36(36)$ & $24(29)$ & $21(27)$ & $2(17)$ & \\
\hline 2 & $6(6)$ & $5(6)$ & $11(14)$ & $2(17)$ & \\
\hline $3-4$ & $1(1)$ & $4(5)$ & $4(5)$ & $0(0)$ & \\
\hline \multicolumn{6}{|l|}{ Previous biologic treatment } \\
\hline Certolizumab pegol & $2(2)$ & $3(4)$ & $2(3)$ & . & \\
\hline Etanercept & $29(29)$ & . & $17(22)$ & $1(8)$ & \\
\hline Adalimumab & . & $25(30)$ & $22(28)$ & $2(17)$ & \\
\hline Golimumab & $5(5)$ & $7(8)$ & . & $2(17)$ & \\
\hline Infliximab & $12(12)$ & $6(7)$ & $14(18)$ & $1(8)$ & \\
\hline
\end{tabular}

BMI body mass index, BASDAI Bath Ankylosing Spondylitis Disease Activity Index, MASES Maastricht Enthesitis Score, BASFI Bath Ankylosing Spondylitis Functional Index, ESR erythrocyte sedimentation rate, CRP C-reactive protein, HLA-B27 human leukocyte antigen B27, $D M A R D$ disease-modifying antirheumatic drug

SASP-using patients, and 23 ADAb-positive vs. 185 ADAbnegative patients with no $\operatorname{SASP}(p=0.68)$.

\section{Drug trough levels and effect of ADAb on trough levels and TNF-blocking capacity}

The mean drug trough concentrations of different TNF inhibitors are presented in Supplementary Table 1. The mean drug trough levels were $8.1 \mathrm{mg} / \mathrm{L}, 1.6 \mu \mathrm{g} / \mathrm{mL}, 1.5 \mu \mathrm{g} / \mathrm{mL}$ and $30.3 \mu \mathrm{g} / \mathrm{mL}$ for adalimumab, etanercept, golimumab and certolizumab, respectively. The mean drug trough concentrations were in the target level in $138(51 \%)$ of the patients. 99 patients $(36 \%)$ had drug concentration lower than the target level and higher than the target drug concentration was detected in $36 \%$ of patients using adalimumab.

The effect of ADAb on drug trough levels in patients using adalimumab is depicted in Fig. 1. At low ADAb concentrations, no clear effect on the drug trough levels could be seen. However, at high ADAb concentrations, decreased drug trough levels are evident, and at the highest ADAb concentration, no measurable drug concentration could be detected.

TNF-blocking capacity reflects the ability of patients' serum to neutralize TNF before next injection of anti-TNF drug. High TNF-blocking capacity (RGA index) means that the patient's sera can still neutralize produced TNF. 
Table 2 Correlation coefficient between drug trough concentration, detected ADAb and TNF alpha blocking capacity (RGA index) to demographics and clinical data

\begin{tabular}{llll}
\hline & Drug trough level $r(95 \%$ CI $)$ & ADAb $(95 \%$ CI $)$ & TNF-blocking capacity (95\% CI) \\
\hline Sex & $0.03(-0.09$ to 0.15$)$ & $-0.12(-0.24$ to -0.01$)$ & $-0.03(-0.14$ to 0.09$)$ \\
Age & $0.20(0.08 \text { to } 0.31)^{* *}$ & $-0.08(-0.20$ to 0.04$)$ & $0.19(0.08 \text { to } 0.30)^{*}$ \\
BMI & $-0.22(-0.33 \text { to }-0.10)^{* *}$ & $0.12(-0.00$ to 0.23$)$ & $-0.15(-0.26$ to -0.03$)$ \\
Disease duration & $0.14(0.02$ to 0.26$)$ & $-0.03(-0.15$ to 0.09$)$ & $0.20(0.09 \text { to } 0.32)^{* *}$ \\
Duration of use of biological & $0.11(-0.01$ to 0.22$)$ & $-0.11(-0.22$ to 0.01$)$ & $0.19(0.08 \text { to } 0.31)^{*}$ \\
$\quad$ drugs & $-0.17(-0.28 \text { to }-0.05)^{*}$ & $0.12(-0.00$ to 0.23$)$ & $-0.02(-0.14$ to 0.10$)$ \\
ESR & $-0.15(-0.26$ to -0.03$)$ & $0.08(-0.04$ to 0.20$)$ & $-0.10(-0.22$ to 0.02$)$ \\
CRP & $-0.06(-0.18$ to 0.06$)$ & $-0.11(-0.22$ to 0.01$)$ & $-0.06(-0.17$ to 0.06$)$ \\
BASDAI & $-0.18(-0.30 \text { to }-0.07)^{*}$ & $0.08(-0.04$ to 0.20$)$ & $-0.14(-0.25$ to -0.02$)$ \\
MASES & $-0.06(-0.18$ to 0.06$)$ & $-0.08(-0.20$ to 0.04$)$ & $-0.02(-0.14$ to 0.10$)$ \\
BASFI &
\end{tabular}

$B M I$ body mass index, ESR erythrocyte sedimentation rate, CRP C-reactive protein, BASDAI Bath Ankylosing Spondylitis Disease Activity Index, MASES Maastricht Enteritis Score, BASFI Bath Ankylosing Spondylitis Functional Index

${ }^{*} p<0.05, * * p<0.01, * * * p<0.001$; statistical significance calculated using Sidak-adjusted probabilities

Table 3 Multivariate logistic regression model for the detected ADAb in patients using adalimumab

\begin{tabular}{lll}
\hline & OR $(95 \%$ CI $)$ & $p$ value \\
\hline Gender & $0.77(0.22-2.72)$ & 0.68 \\
Age & $0.87(0.79-0.95)$ & $\mathbf{0 . 0 0 2}$ \\
BMI & $1.16(1.01-1.32)$ & $\mathbf{0 . 0 3 3}$ \\
Disease duration & $1.13(1.03-1.26)$ & $\mathbf{0 . 0 1 5}$ \\
Total time of use of biologi- & $0.98(0.96-1.00)$ & $\mathbf{0 . 0 4 0}$ \\
$\quad$ cal drug & $3.02(0.38-23.78)$ & 0.29 \\
HLA-B27 & $0.21(0.06-0.76)$ & $\mathbf{0 . 0 1 7}$ \\
csDMARD &
\end{tabular}

$B M I$ body mass index, $H L A-B 27$ human leukocyte antigen $\mathrm{B} 27, c s D$ $M A R D$ conventional synthetic disease-modifying antirheumatic drug

The bold values indicate significance

The TNF-blocking capacity of the patients using adalimumab is depicted as a function of drug trough level in Fig. 2. A clear correlation can be seen between the drug trough level of adalimumab and the TNF-blocking capacity of the patient's serum $(r=0.75,95 \%$ CI $0.64-0.82)$. In patients with high ADAb concentration ( $>23 \mathrm{AU} / \mathrm{mL})$, the TNF-blocking capacity is low, i.e., the patient's serum has low or no ability to neutralize TNF. However, the presence of low concentrations of ADAb $(<23 \mathrm{AU} / \mathrm{mL})$ did not significantly reduce the TNF-blocking capacity, i.e., many of those patients have significant TNF-blocking capacity left before the next injection of the drug. A clear correlation between the drug trough level and the TNF-blocking capacity could be observed also in case of golimumab ( $r=0.79,95 \%$ CI $0.77-0.86)$. Patients with

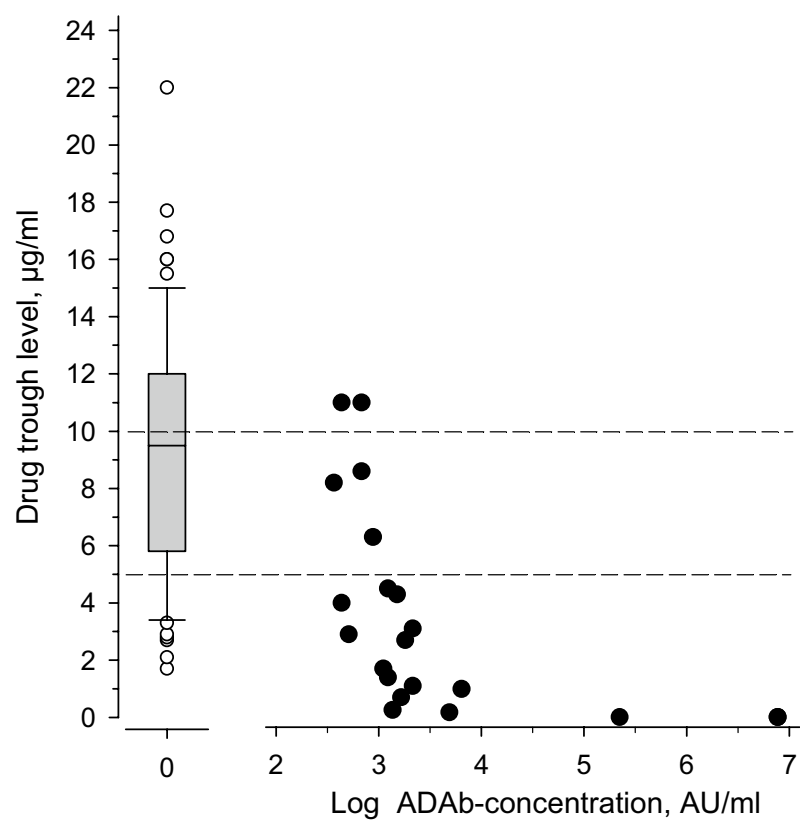

Fig. 1 The association of ADAb concentration and the drug trough level in patients using adalimumab. Left, mean drug trough level of those without detectable ADAb. Right; black dots show the individual values of each patient with detected ADAb. The dotted line indicates the suggested therapeutic drug trough level of adalimumab

positive ADAb in the golimumab group also had low TNFblocking capacity (low RGA index). In case of etanercept, there was no clear correlation between drug trough concentration and the TNF-blocking capacity, as good 

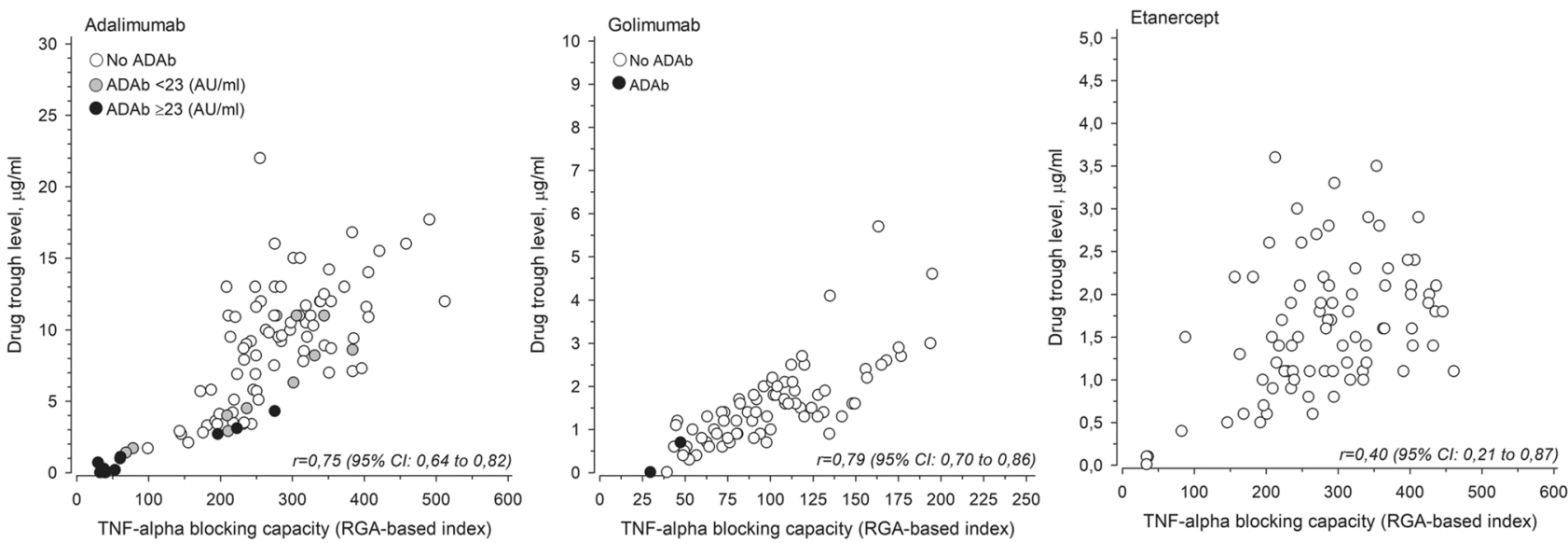

Fig. 2 TNF-blocking capacity of adalimumab, golimumab and etanercept. Gray circles (adalimumab) represent patients with low level of $\mathrm{ADAb}(<23 \mathrm{AU} / \mathrm{mL})$ and black circles patients with high

TNF-blocking capacity could be seen also at relatively low drug concentrations.

\section{Low drug trough level but not the presence of anti-drug antibodies associates with high disease activity}

Significant association was found between low drug trough concentration and high ESR $(p=0.032)$ and high MASES value $(p=0.007)$ in the entire population. Low drug concentration was associated with high MASES also when patients using adalimumab were studied separately $(r=-0.23$ (CI -0.41 to -0.03$), p=0.023$ ). Also the RGA index correlated with MASES; $r=-0.25$ (CI -0.43 to -0.05 ), $p=0.014$. However, no significant correlation was found between drug trough level and BASDAI or between the presence of ADAb and BASDAI. In patients using any anti-TNF drug there was no statistically significant correlation between the presence of ADAb and BASDAI ( $r=-0.18$ (95\% CI -0.36 to 0.02$)$, $p=0.080)$, BASFI $(r=-0.13(95 \% \mathrm{CI}-0.32$ to 0.07$)$, $p=0.21)$, or MASES $(r=0.18(95 \% \mathrm{CI}-0.02$ to 0.36$)$, $p=0.081$ ). Figure 3 shows the BASDAI values in ADAbnegative and ADAb-positive adalimumab users. This reveals that many patients with no ADAb had very high BASDAI values and the number of patients with high level of ADAb was rather low, thus possibly explaining the lack of correlation between ADAb and BASDAI.

\section{Discussion}

In this study, we show that significant proportion of SpA patients using subcutaneous anti-TNF drugs have developed $\mathrm{ADAb}$ against the drug they are using. The significance of level of $\mathrm{ADAb}$ (>23 AU/mL). In golimumab users, black circles represent patients who are positive for $\mathrm{ADAb}$

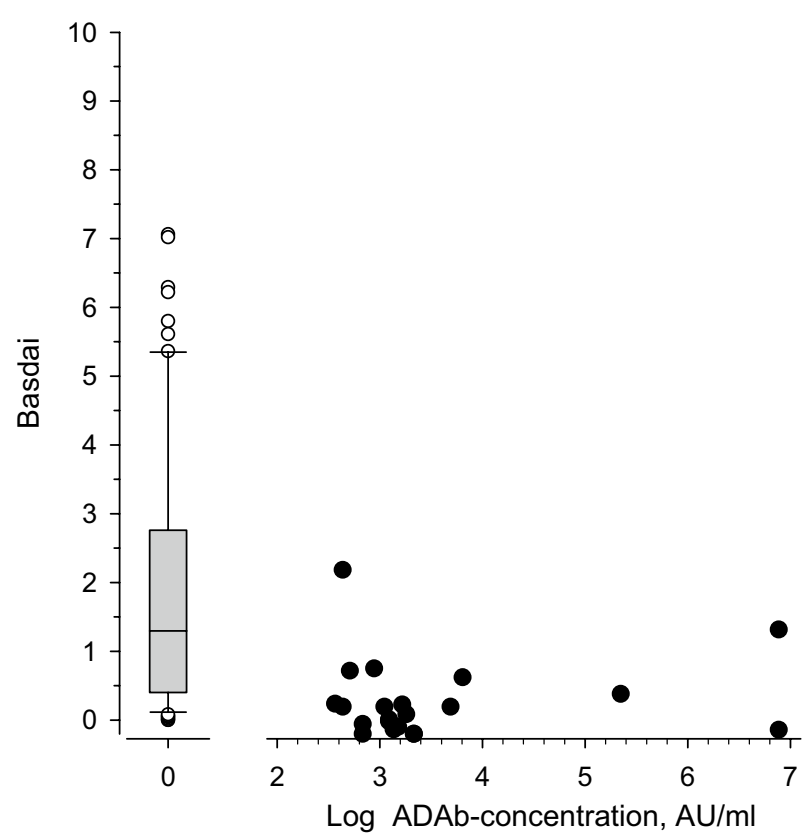

Fig. 3 BASDAI values of AS patients using adalimumab. Left, the mean BASDAI values of patients with no ADAb. Right: The black dots show individual BASDAI values of ADAb-positive patients as a function of ADAb concentration

immunization to biological drugs is not clear in SpA. Bornstein et al. found out that ADAb were detected in $15 \%$ of 39 SpA patients (4/14 on infliximab and 2/16 on adalimumab), of which all had undetectable drug trough levels. ADAb positivity was also associated with higher disease activity [12]. In another study on axSpA patients $27.5 \%$ of patients had anti-adalimumab antibodies. ADAb were associated with lower drug levels and higher clinical activity evaluated by BASDAI and ASDAS [40]. In a recent study by Ducourau 
et al., ADAb were detected in $36.4 \%$ of axSpA patients using adalimumab. Also in this study immunization was associated with lower drug levels and higher clinical activity [7]. These results are concordant with the previously published data showing that most ADAb against adalimumab are neutralizing [41]. In the present study, $11 \%$ of all users of subcutaneous anti-TNF drugs had developed ADAb. As in RA, the highest rate of immunization was observed in patients who used adalimumab (21\%). This is in agreement with previous studies demonstrating ADAb against adalimumab in about $30 \%$ of RA [42] and AS patients [5-7, 43]. It seems that as in the earlier mentioned studies the anti-adalimumab antibodies were neutralizing since all the patients with very low drug trough level were ADAb positive [44]. We did not detect ADAb against etanercept, which is also in agreement with previous studies with patients with SpA [11, 12], AS [13, 43], and RA [23]. Of the patients using golimumab, 3\% had ADAb, also in agreement with previous studies [14-16]. A total of $50 \%$ of certolizumab pegol users were positive for ADAb. However, most of those had drug trough level at the target level, and therefore, the antibodies may not be neutralizing, and thus the clinical significance of the ADAb remains unclear. The number of patients in certolizumab pegol group was also only 12 , and therefore no definite conclusions can be made. In earlier studies, the rate of immunization has been lower in axSpA patients, and anti-certolizumab antibodies have been associated with lower drug levels yet the clinical significance remaining unclear [17, 45]. The number of biologic drugs used earlier did not correlate with immunization.

Patients with concomitant MTX had less frequently ADAb, as compared to those not using MTX, suggesting a protective effect of MTX on immunization also in patients with SpA. In contrast, SASP did not show protective effect against immunization. Higher BMI and longer duration of the disease correlated with the presence of ADAb, and younger age and long duration of biologic treatment correlated negatively with ADAb positivity in adalimumab users.

Lower adalimumab concentrations as well as lower clinical response has been observed in AS or axSpA patients with $\mathrm{BMI}>30$, as compared to those with $\mathrm{BMI}<25$ [46-48]. Theoretically, the lower adalimumab serum levels due to changes in volume distribution could predispose obese patients to immunization against adalimumab. However, in spite of the lower serum drug levels, no difference was observed in rate of immunization [46]. Obesity has been associated with lower TNF inhibitor levels also in RA patients [23] and lower clinical response in patients with rheumatic diseases using TNF inhibitors [49]. In the present study, higher BMI correlated with lower drug trough concentration. Higher BMI also correlated with ADAb positivity in adalimumab users.
The presence of ADAb correlated negatively with drug trough concentration in all the treatment groups in which $\mathrm{ADAb}$ were detected (adalimumab, golimumab, and certolizumab pegol). However, the presence of ADAb did not significantly correlate with disease activity. This is most likely explained by the fact that low levels of ADAb did not have significant effect on drug trough levels. As shown in Fig. 2 patients with low levels of ADAb had significant remaining TNF-blocking capacity, and only in those with high levels of ADAb the TNF-blocking capacity was low. As this study was cross-sectional, it is impossible to know whether the patients with low level of ADAb later developed higher ADAb levels or lost their treatment response. Low drug trough levels were associated with higher disease activity, as reflected by the association with higher ESR and higher MASES.

A correlation was observed between adalimumab and golimumab drug trough level and the TNF-blocking capacity expressed as RGA index. In case of etanercept, no clear correlation could be observed between the TNF-blocking capacity and the drug trough level, as the TNF-blocking capacity was good also at lower drug concentrations. The reason for this is not clear. Also, in earlier studies, the clinical relevance of drug level of etanercept seems to be somewhat controversial in patients with both AS $[13,50]$ and RA [23, 51].

Based on these results, we believe that measuring drug concentration and ADAb in SpA patients using TNF inhibitors with the exception of etanercept is useful both in patients with active disease, but also in those patients who seem to respond to therapy to avoid unnecessary treatment in those who have been immunized to the drug and have therefore unmeasurable drug levels. This is supported by a recent study by Pedersen et al. who showed that therapeutic drug monitoring of TNF inhibitors leads to better clinical response and cost management in the treatment of patients with rheumatic diseases [52]. A recent review concluded that measuring drug levels and ADAb in RA and SpA patients with biologic treatment might be useful both in case of poor response and longer clinical remission [53].

The study has several limitations. The aim of the study was to evaluate the extent and significance of immunization in unselected patients coming to regular outpatient visit. Our study is a cross-sectional study, and thus it does not allow the analysis of the kinetics of immunization to TNF alpha inhibitors or allow the follow up of the patients. Although the study population is relatively large the subgroups of patients using certolizumab pegol and ADAb-positive group of patients using golimumab are rather small, which makes it difficult to draw conclusions concerning immunization and its clinical relevance in these subgroups of patients. 


\section{Conclusion}

A significant proportion of patients had been immunized to the subcutaneous anti-TNF drug they were using. The presence of ADAb was associated with lower drug concentration and reduced TNF-blocking capacity. Low drug trough levels correlated with higher ESR and MASES. The use of MTX reduced the risk for immunization in patients with SpA, whereas SASP did not. There was no clear correlation between ADAb and the BASDAI, BASFI or MASES scores, likely because the low ADAb levels had no significant effect on TNF-blocking capacity. Thus the significance of finding of low ADAb level in patients is not clear. It is likely that patients with high drug antibody levels and low drug trough concentrations do not benefit from the drug they are using. Thus, measuring of drug trough level and ADAb may be useful to optimize treatment individually and achieve better cost management.

Supplementary Information The online version contains supplementary material available at https://doi.org/10.1007/s00296-021-04955-8.

Acknowledgements FinADASpA study group: Arto Kokko, Jyväskylä Central Hospital, Department of Medicine, Jyväskylä, Finland, Aulikki Kononoff, Elina Savolainen, Julia Barantseva, Antti Puolitaival and Tuomas Rannio, Kuopio University Hospital, Department of Rheumatology, Kuopio, Finland, llpo Koskivirta, Johanna Paltta, Maija Puurtinen-Vilkki, Markku Mali, Turku University Hospital, Department of Rheumatology, Turku, Finland, Jarno Rutanen, Tampere University Hospital, Department of Rheumatology.

Author contributions JH: writing-original draft, writing-review and editing; PP: investigation; TS: investigation, writing-review and editing; TL: investigation; PI: investigation; OK-S: investigation, writing — review and editing; RP: investigation, writing-review and editing; TU: investigation; LP: investigation; KT: investigation; MJK: investigation, writing - review and editing; TY-K: investigation; RT: investigation; HR: investigation; SK: investigation; KP: investigation; JA: investigation; PE: investigation; AS: investigation; K-LV: investigation; KT: investigation; MR: investigation; JB: investigation; PE: investigation; HV: investigation; ML-R: investigation, writing-review and editing; VR: investigation; HK: data curation, software, formal analysis, visualization; TSJ: conceptualization, methodology, resources, writing - review and editing; KKE: conceptualization, methodology, project administration, supervision, funding acquisition, investigation, writing - review and editing. All co-authors take full responsibility for all aspects of the work.

Funding Open access funding provided by University of Helsinki including Helsinki University Central Hospital. This study was supported by an independent research grant from Pfizer (Grant Number WI189027). Pfizer did not have any influence on planning, executing, interpretation or reporting of the data.

Data availability All data of the study is available upon reasonable request.

Code availability Not applicable.

\section{Declarations}

Conflict of interest Dr. Hiltunen reports non-financial support from Pfizer (congress costs), outside the submitted work. Dr. Parmanne reports non-financial support from Novartis, Pfizer and Abbvie, outside the submitted work. Dr. Sokka-Isler reports non-financial support from DiaGraphIT, personal fees from Abbvie, BMS, Celgene, Medac, Merck, Novartis, Orion Pharma, Pfizer, Roche, Sandoz, UCB and Bohringer Ingelheim, outside the submitted work. Dr. Isomäki reports personal fees and non-financial support from Abbvie, personal fees from Lilly, Pfizer, personal fees and non-financial support from Roche, outside the submitted work. Dr. Kaipiainen-Seppänen reports non-financial support from Novartis and Pfizer, outside the submitted work. Dr. Pirilä reports personal fees from Mylan Finland, Novartis Finland, Abbvie Oy, Boeringer Ingelheim, Pfizer, Swedish Orphan Biotirum and Viatris, other support from Oriola Finland, Sanofi, Jansen Cilat and Eli Lilly Finland, outside the submitted work. Dr. Kauppi reports personal fees from Abbvie, Eli Lilly Finland, MSD, Novartis/Sandoz, Pfizer, Roche, UCB and Berlin-Chenie Menarini, outside the submitted work. Dr. Yli-Kerttula reports personal fees from MSD, Pfizer, BMS and Abbvie, outside the submitted work. Dr. Tuompo reports personal fees from Viatris, non-financial support from Novartis and Viatris, outside the submitted work. Dr. Relas reports personal fees from Abbvie, Celgene and Pfizer, outside the submitted work. Dr. Paalanen reports non-financial support from Celgene, Sandoz, non-financial support and other from Pfizer, personal fees and other from Orion Pharma, non-financial support and other support from MSD, non-financial support and other support from Medac, non-financial support and other support from Roche, non-financial support from Sanofi, outside the submitted work. Dr. Vidqvist reports personal fees (lecturer fees and advisory board): Abbvie, Boeringer-Ingelheim, Novartis, Pfizer and UCB. Dr. Tadesse reports non-financial support from Novartis, outside the submitted work. Dr. Borodina reports non-financial support from Novartis, Roche and Eli Lilly, outside the submitted work. Dr. Elfving reports personal fees from Abbvie (lecture fee) and Astra Zeneca (consultation fee), non-financial support from Pfizer and Mylan (congress costs), outside the submitted work. Dr. Rantalaiho reports congress grants from Mylan, Abbvie and Pfizer, and a study grant from BMS for NordStar trial, outside the submitted work. Dr. Jokiranta reports grants from Pfizer, during the conduct of the study; personal fees from Abbvie, Alexion Pharmaceuticals, Bristol- Myers Squibb, Eli Lilly Finland, Medac, Medscape, MSD, Novartis/Sandoz, Pfizer, Roche, Scopeful, Takeda, UCB, United Medix Laboratories and Tammer BioLab, outside the submitted work. Dr. Eklund reports grants from Pfizer, during the conduct of the study. PhD. Lamberg, Dr. Peltomaa, Dr Uutela, Dr. Taimen, Dr. Kortelainen, Dr. Asikainen, Dr. Ekman, Dr. Santisteban, Dr. Romu, Dr. Valleala, Dr. Leirisalo-Repo and Mr. Kautiainen have nothing to disclose.

Ethical approval The study protocol was approved by the Ethical Review Board of the Joint Authority for the Hospital District of Helsinki and Uusimaa (108/13/03/01/2014).

Consent to participate All the patients gave an informed written consent.

Consent for publication All of the authors have given the permission for publication.

Open Access This article is licensed under a Creative Commons Attribution 4.0 International License, which permits use, sharing, adaptation, distribution and reproduction in any medium or format, as long as you give appropriate credit to the original author(s) and the source, provide a link to the Creative Commons licence, and indicate if changes were made. The images or other third party material in this article are 
included in the article's Creative Commons licence, unless indicated otherwise in a credit line to the material. If material is not included in the article's Creative Commons licence and your intended use is not permitted by statutory regulation or exceeds the permitted use, you will need to obtain permission directly from the copyright holder. To view a copy of this licence, visit http://creativecommons.org/licenses/by/4.0/.

\section{References}

1. de Vries MK, Wolbink GJ, Stapel SO et al (2007) Decreased clinical response to infliximab in ankylosing spondylitis is correlated with anti-infliximab formation. Ann Rheum Dis 66:1252-1254

2. Méric J-C, Mulleman D, Ducourau E et al (2011) Therapeutic drug monitoring of infliximab in spondyloarthritis: an observational open-label study. Ther Drug Monit 33:411-416

3. Ducourau E, Mulleman D, Paintaud G et al (2011) Antibodies toward infliximab are associated with low infliximab concentration at treatment initiation and poor infliximab maintenance in rheumatic diseases. Arthritis Res Ther 13(3):R105

4. Plasencia C, Pascual-Salcedo D, Nuño L et al (2012) Influence of immunogenicity on the efficacy of long-term treatment of spondyloarthritis with infliximab. Ann Rheum Dis 71:1955-1960

5. de Vries MK, Brouwer E, van der Horst-Bruinsma IE et al (2009) Decreased clinical response to adalimumab in ankylosing spondylitis is associated with antibody formation. Ann Rheum Dis 68:1787-1788

6. Kneepkens EL, Wei JC, Nurmohamed MT et al (2015) Immunogenicity, adalimumab levels and clinical response in ankylosing spondylitis patients during 24 weeks of follow-up. Ann Rheum Dis 74:396-401

7. Ducourau E, Rispens T, Samain M, Dernis E, Le Guilchard F, Andras L, Perdriger A, Lespessailles E, Martin A, Cormier G, Armingeat T, Devauchelle-Pensec V, Gervais E, Le Goff B, de Vries A, Piver E, Paintaud G, Desvignes C, Ternant D, Watier H, Goupille P, Mulleman D (2020) Methotrexate effect on immunogenicity and long-term maintenance of adalimumab in axial spondyloarthritis: a multicentric randomized trial. RMD Open 6(1):001047. https://doi.org/10.1136/rmdopen-2019-001047

8. Paramarta JE, Baeten DL (2014) Adalimumab serum levels and antidrug antibodies towards adalimumab in peripheral spondyloarthritis: no association with clinical response to treatment or with disease relapse upon treatment discontinuation. Arthritis Res Ther 16(4):R160

9. Cludts I, Spinelli RF, Morello F, Hockley J, Valesini G, Wadhwa M (2018) Anti-therapeutic antibodies and their clinical impact in patients treated with the TNF antagonist adalimumab. Cytokine 101:70-77

10. Maneiro JR, Salgado E, Gomez-Reino JJ (2013) Immunogenicity of monoclonal antibodies against tumor necrosis factor used in chronic immune- mediated inflammatory conditions: systematic review and meta-analysis. JAMA Intern Med 173(15):1416-1428

11. Spinelli FR, Valesini G (2013) Immunogenicity of anti-tumor necrosis factor drugs in rheumatic diseases. Clin Exp Rheumatol 31(6):954-963

12. Bornstein G, Lidar M, Langevitz $P$ et al (2018) The prevalence and clinical effect of immunogenicity of TNF (alpha) blockers in patients with axial SpA. Clin Exp Rheumatol 36:228-232

13. de Vries MK, van der Horst-Bruinsma IE, Nurmohamed MT et al (2009) Immunogenicity does not influence treatment with etanercept in patients with ankylosing spondylitis. Ann Rheum Dis 68:531-535
14. Deodhar A, Braun J, Inman RD et al (2015) Golimumab administered subcutaneously every 4 weeks in ankylosing spondylitis: 5-year results of the GO-RAISE study. Ann Rheum Dis 74(4):757-761

15. Inman RD, Davis JC Jr, Heijde D et al (2008) Efficacy and safety of golimumab in patients with ankylosing spondylitis: results of a randomized, double-blind, placebo-controlled, phase III trial. Arthritis Rheum 58(11):3402-3412

16. Sieper J, van der Heijde D, Dougados M et al (2015) A randomized, double-blind, placebo-controlled, sixteen-week study of subcutaneous golimumab in patients with active non-radiographic axial spondyloarthritis. Arthritis Rheum 67(10):2702-2712

17. Sieper J, Landewé R, Rudwaleit M et al (2015) Effect of certolizumab pegol over ninety-six weeks in patients with axial spondyloarthritis: results from a phase III randomized trial. Arthritis Rheum 67(3):668-677

18. Jani M, Isaacs JD, Morgan AW (2016) High frequency of antidrug antibodies and association of random drug levels with efficacy in certolizumab pegol-treated patients with rheumatoid arthritis: results from the BRAGGSS cohort. Ann Rheum Dis. https://doi. org/10.1136/annrheumdis-2015-208849

19. Wolbink GJ, Voskuyl AE, Lems WF et al (2005) Relationship between serum trough infliximab levels, pretreatment $C$ reactive protein levels, and clinical response to infliximab treatment in patients with rheumatoid arthritis. Ann Rheum Dis 64(5):704-707

20. Pouw MF, Krieckaert CL, Nurmohamed MT et al (2015) Key findings towards optimizing adalimumab treatment: the concentrationeffect curve. Ann Rheum Dis 74(3):513-518

21. Chen D-Y, Chen YM, Tsai W-C et al (2015) Significant associations of antidrug antibody levels with serum drug trough levels and therapeutic response of adalimumab and etanercept treatment. Ann Rheum Dis 74(3):e.16

22. Kneepkens EL, Plasencia C, Krieckaert CL et al (2014) Golimumab trough levels, anti-drug antibodies, and clinical response in patients with rheumatoid arthritis treated in daily clinical practice. Ann Rheum Dis 73(12):2217

23. Jani M, Chinoy H, Warren RB et al (2015) Clinical utility of random anti-tumor necrosis factor drug-level testing and measurement of antidrug antibodies on the long-term treatment response in rheumatoid arthritis. Arthritis Rheum 67(8):2011-2019

24. Goss SL, Klein CE, Jin Z et al (2018) Methotrexate dose in patients with early rheumatoid arthritis impacts methotrexate polyglutamate pharmacokinetics, adalimumab pharmacokinetics, and efficacy: pharmacokinetic and exposure-response analysis of the Concerto trial. Clin Ther 40:309-319

25. Krieckaert CL, Nurmohamed MT, Wolbink GJ (2012) Methotrexate reduces immunogenicity in adalimumab treated rheumatoid arthritis patients in a dose dependent manner. Ann Rheum Dis 71:1914-1915

26. Krieckaert CLM, Bartelds GM, Lems WF, Wolbink GJ (2010) The effect of immunomodulators on the immunogenicity of TNFblocking therapeutic monoclonal antibodies: a review. Arthritis Res Ther 12(5):217

27. Nam JL, Winthrop KL, van Vollenhoven RF et al (2010) Current evidence for the management of rheumatoid arthritis with biological disease-modifying antirheumatic drugs: a systematic literature review informing the EULAR recommendations for the management of RA. Ann Rheum Dis 69(6):976-986

28. Ward MM, Deodhar A, Gensler LS, Dubreuil M, Yu D, Khan MA et al (2019) 2019 Update of the American College of Rheumatology/Spondylitis Association of America/Spondyloarthritis Research and Treatment Network recommendations for the treatment of ankylosing spondylitis and nonradiographic axial spondyloarthritis. Arthritis Rheumatol 71(10):1599-1613

29. Garcês S, Demengeot J, Benito-Garcia E (2013) The immunogenicity of anti-TNF therapy in immune-mediated inflammatory 
diseases: a systematic review of the literature with a meta-analysis. Ann Rheum Dis 72(12):1947-1955

30. Pérez-Guijo VC, Cravo AR, Mdel CC, Font P, Muñoz-Gomariz E, Collantes-Estevez E (2007) Increased efficacy of infliximab associated with methotrexate in ankylosing spondylitis. Joint Bone Spine 74:254-258

31. Mulleman D, Lauferon F, Wendling D et al (2011) Infliximab in ankylosing spondylitis: alone or in combination with methotrexate? A pharmacokinetic comparative study. Arthritis Res Ther 13(3):R82

32. Breban M, Ravaud P, Claudepierre P et al (2008) Maintenance of infliximab treatment in ankylosing spondylitis: results of a oneyear randomized controlled trial comparing systematic versus ondemand treatment. Arthritis Rheum 58:88-97

33. Lie E, Kristensen LE, Forsblad-d'Elia H, Zverkova-Sandström T, Askling J, Jacobsson LT, ARTIS Study Group (2015) The effect of comedication with conventional synthetic disease modifying antirheumatic drugs on TNF inhibitor drug survival in patients with ankylosing spondylitis and undifferentiated spondyloarthritis: results from a nationwide prospective study. Ann Rheum Dis 74(6):970-978

34. Garrett S, Jenkinson T, Kennedy LG, Whitelock H, Gaisford $\mathrm{P}$, Calin A (1994) A new approach to defining disease status in ankylosing spondylitis: the Bath Ankylosing Spondylitis Disease Activity Index. J Rheumatol 12:2286-2291

35. Heuft-Dorenbosch L, Spoorenberg A, van Tubergen A et al (2003) Assessment of enthesistis in ankylosing spondylitis. Ann Rheum Dis 62:127-132

36. Calin A, Garret S, Whitelock $\mathrm{H}$ et al (1994) A new approach to defining functional ability in ankylosing spondylitis: the development of the Bath Ankylosing Spondylitis Functional Index. J Rheumatol 21:2281-2285

37. Bendtzen K (2015) Immunogenicity of anti-TNF- $\alpha$ biotherapies: II. Clinical relevance of methods used for anti-drug antibody detection. Front Immunol 6:109

38. Ducourau E, Ternant D, Lequerré T et al (2014) Towards an individualized target concentration of adalimumab in rheumatoid arthritis. Ann Rheum Dis 73(7):1428-1429

39. Brunner H, Ruperto N, Tzaribachev N et al (2018) Subcutaneous golimumab for children with active polyarticular-course juvenile idiopathic arthritis: results of a multicentre, double-blind, randomised-withdrawal trial. Ann Rheum Dis 77(1):21-29

40. Gallego JMS, Rosas J, Marco-Mingot M et al (2019) Clinical relevance of monitoring serum adalimumab levels in axial spondyloarthritis. Rheumatol Int 39(5):841-849

41. van Schouwenburg PA, van de Stadt LA, de Jong RN, van Buren EE, Kruithof S, de Groot E, Hart M, van Ham SM, Rispens T, Aarden L, Wolbink GJ, Wouters D (2013) Adalimumab elicits a restricted anti-idiotypic antibody response in autoimmune patients resulting in functional neutralization. Ann Rheum Dis 72:104-109

42. Bartelds GM, Krieckaert CL, Nurmohamed MT et al (2011) Development of antidrug antibodies against adalimumab and association with disease activity and treatment failure during long-term follow-up. JAMA 305(14):1460-1468

\section{Authors and Affiliations}

43. Arends S, Lebbink HR, Spoorenberg A et al (2010) The formation of autoantibodies and antibodies to TNF- $\alpha$ blocking agents in relation to clinical response in patients with ankylosing spondylitis. Clin Exp Rheumatol 28(5):661-668

44. van Schouwenburg PA, Rispens T, Wolbink GJ (2013) Immunogenicity of anti-TNF biologic therapies for rheumatoid arthritis. Nat Rev Rheumatol 9(3):164-172

45. Gehin JE, Goll GL, Warren DJ, Syversen SW, Sexton J, Strand EK, Kvien TK, Bolstad N, Lie E (2018) FRI0645 Anti-drug antibodies to certolizumab pegol are associated with low drug levels and reduced clinical response at 3 months in patients with inflammatory joint diseases. Data from the NOR-DMARD study. Ann Rheum Dis 77(Suppl 2):844

46. Rosas J, Llinares-Tello F, Senabre-Gallego JM et al (2017) Obesity decreases clinical efficacy and levels of adalimumab in patients with ankylosing spondylitis. Clin Exp Rheumatol 35(1):145-148

47. Micheroli R, Hebeisen M, Wildi LM, Exer P, Tamborrini G, Bernhard J, Möller B, Zufferey P, Nissen MJ, Scherer A, Ciurea A (2017) Impact of obesity on the response to tumor necrosis factor inhibitors in axial spondyloarthritis. Arthritis Res Ther 19(1):164

48. Gremese E, Bernardi S, Bonazza S, Nowik M, Peluso G, Massara A, Tolusso B, Messuti L, Miceli MC, Zoli A, Trotta F, Govoni M, Ferraccioli G (2014) Body weight, gender and response to TNF- $\alpha$ blockers in axial spondyloarthritis. Rheumatology 53(5):875-881

49. Singh S, Faggiorusso A, Singh AG et al (2018) Obesity and response to anti-tumor necrosis factor agents in patients with select immune-mediated inflammatory diseases: a systematic review and meta-analysis. PLoS ONE 13(5):e0195123

50. Kneepkens EL, Krieckaert CL, van der Kleij D et al (2015) Lower etanercept levels are associated with high disease activity in ankylosing spondylitis patients at 24 weeks of follow-up. Ann Rheum Dis 74(10): $1825-1829$

51. Jamnitski A, Krieckaert CL, Nurmohamed MT et al (2012) Patients non-responding to etanercept obtain lower etanercept concentrations compared with responding patients. Ann Rheum Dis 71(1):88-91

52. Pedersen L, Szecsi PB, Bjerrum PJ, Johansen PB (2020) Evaluation of therapeutic drug monitoring in the clinical management of patients with rheumatic diseases: data from a retrospective singlecenter cohort study. Biologics 14:115-125

53. Martín-López M, Carmona L, Balsa A, Calvo-Alén J, Sanmartí R, Tornero J, Rosas J (2018) Serum drug levels of biologic agents in the management of rheumatoid arthritis and spondyloarthritis: a systematic review. Rheumatol Int 38(6):975-983. https://doi.org/ 10.1007/s00296-018-4022-4

Publisher's Note Springer Nature remains neutral with regard to jurisdictional claims in published maps and institutional affiliations.

\section{J. Hiltunen ${ }^{1}$ (I) P. Parmanne ${ }^{1} \cdot$ T. Sokka $^{2,3} \cdot$ T. Lamberg $^{4} \cdot$ P. Isomäki ${ }^{5} \cdot$ O. Kaipiainen-Seppänen ${ }^{6} \cdot$ R. Peltomaa ${ }^{1}$.

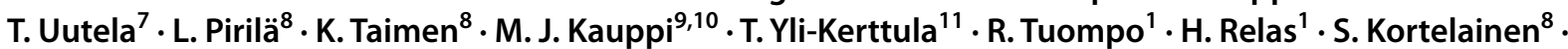 K. Paalanen ${ }^{2,3}$. J. Asikainen ${ }^{2,3} \cdot$ P. Ekman ${ }^{11} \cdot$ A. Santisteban ${ }^{15} \cdot$ K.-L. Vidqvist ${ }^{5} \cdot K_{\text {. Tadesse }}{ }^{1} \cdot$ M. Romu ${ }^{1} \cdot$ J. Borodina $^{2,3}$. P. Elfving ${ }^{6} \cdot$ H. Valleala ${ }^{1} \cdot$ M. Leirisalo-Repo ${ }^{1} \cdot$ V. Rantalaiho $^{5} \cdot$ H. Kautiainen ${ }^{12} \cdot$ T. S. Jokiranta ${ }^{13} \cdot$ K. K. Eklund ${ }^{1,14} \cdot$ for $^{2}$ the FinADASpA Study Group}

P. Parmanne

pinja.parmanne@hus.fi
T. Sokka

tuulikki.sokka-isler@ksshp.fi 
T. Lamberg

tea.lamberg@medix.fi

P. Isomäki

pia.isomaki@tuni.fi

O. Kaipiainen-Seppänen

oili.kaipiainen-seppanen@kuh.fi

R. Peltomaa

ritva.peltomaa@hus.fi

T. Uutela

toini.uutela@fimnet.fi

L. Pirilä

laura.pirila@fimnet.fi

K. Taimen

kirsi.taimen@tyks.fi

M. J. Kauppi

markku.kauppi@phhyky.fi

T. Yli-Kerttula

timo.yli-kerttula@satshp.fi

R. Tuompo

riitta.tuompo@hus.fi

H. Relas

heikki.relas@hus.fi

S. Kortelainen

saara.kortelainen@tyks.fi

K. Paalanen

kirsi.paalanen@ksshp.fi

J. Asikainen

juha.asikainen@ksshp.fi

P. Ekman

paivi.ekman@satshp.fi

A. Santisteban

antonio.santisteban@essote.fi

K.-L. Vidqvist

krista-liisa.vidqvist@pshp.fi

K. Tadesse

kura.tadesse@hus.fi

M. Romu

matti.romu@hus.fi

J. Borodina

jelena.borodina@ksshp.fi

P. Elfving

pia.elfving@kuh.fi
H. Valleala

heikki.valleala@hus.fi

M. Leirisalo-Repo

ext-marjatta.leirisalo-repo@hus.fi

V. Rantalaiho

vappu.rantalaiho@tuni.fi

H. Kautiainen

hannu.kautiainen@medcare.fi

T. S. Jokiranta

sakari.jokiranta@medix.fi

K. K. Eklund

kari.eklund@hus.fi

1 Department of Rheumatology, Helsinki University

and Helsinki University Hospital, Haartmaninkatu 4, P. O.

Box 372, 00029 HUS Helsinki, Finland

2 Department of Rheumatology, Jyväskylä Central Hospital, Jyväskylä, Finland

3 University of Eastern Finland, Kuopio, Finland

4 United Medix Laboratories, Helsinki, Finland

5 Department of Rheumatology, Tampere University Hospital, Tampere, Finland

6 Department of Rheumatology, Kuopio University Hospital, Kuopio, Finland

7 Department of Rheumatology, Central Hospital of Lapland, Rovaniemi, Finland

8 Department of Rheumatology, Turku University Hospital, Turku, Finland

9 Department of Rheumatology, Päijät-Häme Central Hospital, Lahti, Finland

10 University of Tampere, Tampere, Finland

11 Department of Rheumatology, Satakunta Central Hospital, Rauma, Finland

12 Medcare Foundation, Äänekoski, Finland

13 SYNLAB Finland, Helsinki, Finland

14 Translational Immunology Research Program, Helsinki University and Orton Research Foundation, Orton Hospital, Helsinki, Finland

15 Departmentof Rheumatology, Mikkeli Central Hospital, Mikkeli, Finland 